\title{
A GENERAL METHOD OF BRAKING PROCESS SIMULATION FOR FLEXIBLE MARSHALLING EMUS
}

\author{
TIANHE MA, MENGLING WU \& CHUN TIAN \\ Institute of Rail Transit, Tongji University, China.
}

\begin{abstract}
Electropneumatic brake systems are widely used on electric multiple units (EMUs) for high-speed railway and urban rail transit. The common marshalling of the EMUs varies from four to eight cars for urban mass transit and even 16 cars for high-speed way. Traditional methods for braking calculation, which are only suitable for unit-fixed and marshalling-fixed EMUs, are not able to deal with complicated braking process and various marshalling. In this article, a general method for flexible marshalling train braking process simulation is proposed. This method deals with an EMU consisting of 1-24 cars by dividing it into one to eight units and each unit has one to three cars. During braking of EMUs, braking force is calculated according to brake level and velocity, and then managed and applied according to units' type and distributing principle. With this method, braking deceleration, speed, distance and electric braking force, pneumatic braking force and brake cylinder pressure of each car at any time during the whole braking process can be all presented. Simulation covers braking instruction transmission, braking force calculation and management at train level, electric pneumatic blending braking force distribution at unit level and braking force application at vehicle level. Simulation has been validated by field test results. Finally, an instance of simulation for a custom marshalling EMU is presented. The method can not only meet the needs of engineers and technicians to do brake calculation and braking performance validation of the existing fixed marshalling EMUs, but also provide reference for new design of novel flexible marshalling EMUs.

Keywords: braking process, electric pneumatic blending brake, EMUs, flexible marshalling.
\end{abstract}

\section{INTRODUCTION}

At present, there are two main methods of braking simulation, one is modelling and the other is identification. Modelling methods establish the mathematical model of braking systems based on the structure of components of the system, using theory of fluid mechanics, thermodynamics, etc. [1-4]. Identification methods usually place emphasis on the input and output of a system based on the test data and ignoring the internal mechanism [5-8]. Luo et al. [1] built a detailed model of an electropneumatic brake used on subway train by decomposing it into smaller modules at three levels. Pugi et al. [2] proposed a simulation model library for a UIC pneumatic brake system, including elementary components such as pipes, orifices, valves and the reservoirs. Piechowiak [3] took into account air-wave phenomena including air viscosity, the influence of the brake pipe branches, heat transfer in the brake pipes and reservoirs, air flows in the brake valves and the dynamics of moving mechanical parts to build the mathematical model of a freight train brake. Richer and Hurmuzlu [4] developed a detailed mathematical model of dual-action pneumatic actuators controlled with proportional spool valves. Li et al. [5] built a third-order distributed autoregressive model for the braking process of electric multiple units (EMUs) by analysing the relationship between braking force and vehicle velocity. Guo and Xie [6] built the Hammerstein model of EMU braking system by dividing braking process into three links. Yu and Chen [7] proposed a braking model for urban rail train and a method of parameter identification. 
Yang et al. [8] proposed a data-driven modelling method for braking process based on operation characteristics and brake deceleration mode curve. There are some methods to build models and simulate the braking process by softwares such as Simulink, Simpack and AMESim [9, 10].

Modelling based on mechanism can get a very detailed model, but the physical parameters are difficult to be obtained and the simulation is usually time-consuming. For a braking process analysis of a whole train, instead of analysis of a detailed valve or other components, identification method is more suitable. With the vigorous development of rail transit, more and more EMUs are in service. For different marshalling of trains, the calculation and distribution of braking forces are different, which brings challenge to the traditional braking simulation. So in this article, a general method to handle flexible marshalling EMUs braking process simulation is proposed to solve the problem of braking force calculation and distribution when simulating a braking process.

The remaining sections of this article are organized as follows: in Section 2, we introduced the typical braking process of EMUs and analysed the principle of braking system. Section 3 proposed the simulation method of braking process for flexible marshalling EMU trains and validated the braking distance simulation results by field test data. Section 4 shows the simulation result of a custom marshalling EMU train and gives a discussion. Finally, a conclusion is drawn in Section 5 .

\section{BRAKING PROCESS ANALYSIS}

EMU trains generally use microcomputer-controlled direct acting electropneumatic braking system. A train is divided into several units composed of a number of motor cars and trailers. In a braking process, braking devices of each unit work independently. When the instructions are sent, electric braking forces apply at first, and then the insufficient force is supplemented by the pneumatic braking forces.

As shown in Fig. 1, a six-car EMU train is divided into two units, each consisting of two motor cars and one trailer. During braking, the EBCU of the motor car receives the control command from the $\mathrm{CCU}$ or the driver, calculates the braking force according to the target deceleration corresponding to the load and the current speed, and then requests for the electric braking force from the TCU. The feedback electric braking force determines the air braking forces for the trailer and motor cars to supplement. The electric braking force is generated by the traction motor working in the generator mode. The pneumatic braking force is generated by the electromagnetic valves and pneumatic valves in the PBCU to generate a certain pressure of compressed air in brake cylinders to get the friction force. The braking forces and resistance give the train a deceleration and then the speed can be reduced until the train stops (Fig. 2).

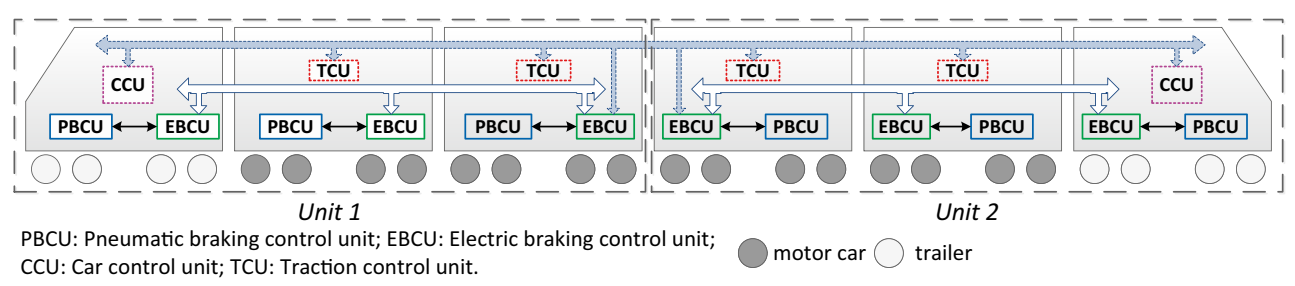

Figure 1: Braking system topology of an EMU train. 


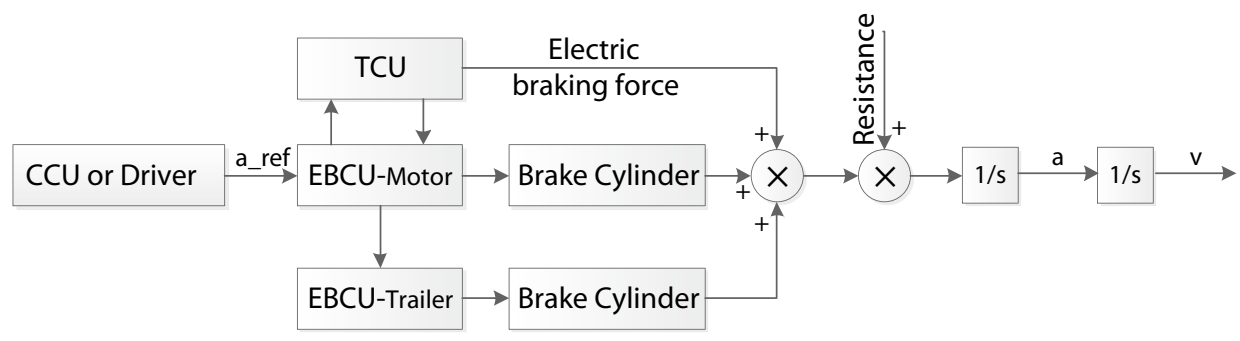

Figure 2: Braking process schematic.

\section{METHOD}

The braking process can be divided into the process of braking force calculation and distribution (also called brake management) as well as braking force exertion. The former changes with the train configuration such as marshalling and the latter relates to the brake's structure parameters and control performance. For the simulation of braking force calculation and distribution, traditional methods [11] can only handle existing EMU trains with a definite unit form and a fixed number of cars, which lacks flexibility. This article proposes a generic method that introduces a code array for motor and trailer cars that can be used to simulate the braking management process for different marshalling EMU trains generally.

\subsection{Marshalling analysis and coding method}

High-speed trains and subway trains are basically power-dispersible EMU trains consisting of a number of units (Fig. 3). For a simulation, a train with different number of cars, type of cars and cars' positions in the train has different braking force curves. A survey of EMU trains that are currently in service in China is conducted, and the marshalling of the eight kinds of trains is summarized in Table 1 (models are code-named). The shortest grouping consists of eight cars, including 4M4T and 6M2T, and the maximum grouping is 16 car marshalling, i.e. 8M8T and 14M2T. The types of all the units are TM, MT, TMM, MMT and M. Since the result of the braking simulation needs to correspond to each vehicle, the order of the vehicles within the grouping is significant, which means TM and MT as well as TMM and MMT need to be treated as different types of units.

To cover the existing kinds of trains and meet the needs of new designs of EMUs, eight reasonable basic units, i.e. T, M, TM, MT, MM, TMM, MTM and MMT, were determined. Since the number of passenger train formations does not exceed 16 in general, eight arrays are defined to express eight units of a train. Each array has eight possible encoding forms, which are $[0],[1],[0,1],[1,0],[1,1],[0,1,1],[1,0,1]$ and $[1,1,0]$. Each code corresponds to a

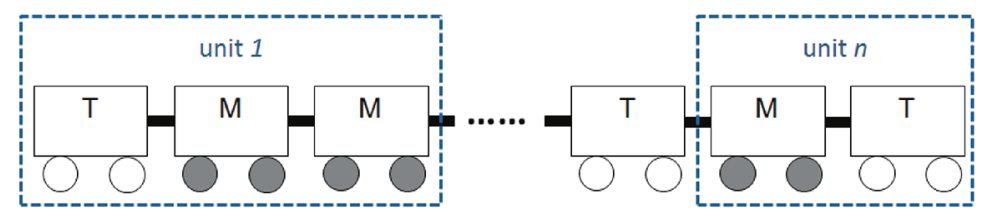

Figure 3: Marshalling of EMU trains. 
Table 1: Marshalling form of part of the existing EMU trains (T: trailer M: motor car).

\begin{tabular}{lll}
\hline EMU trains & Marshalling & Units \\
\hline R1 & $4 \mathrm{M} 4 \mathrm{~T}$ & $\mathrm{TM}+\mathrm{MT}+\mathrm{TM}+\mathrm{MT}$ \\
R2 & $8 \mathrm{M} 8 \mathrm{~T}$ & $\mathrm{TM}+\mathrm{MT}+\mathrm{TM}+\mathrm{MT}+\mathrm{TM}+\mathrm{MT}+\mathrm{TM}+\mathrm{MT}$ \\
R3 & $6 \mathrm{M} 2 \mathrm{~T}$ & $\mathrm{TMM}+\mathrm{M}+\mathrm{M}+\mathrm{MMT}$ \\
R4 & $6 \mathrm{M} 2 \mathrm{~T}$ & $\mathrm{TMM}+\mathrm{M}+\mathrm{M}+\mathrm{MMT}$ \\
R5 & $6 \mathrm{M} 2 \mathrm{~T}$ & $\mathrm{TMM}+\mathrm{M}+\mathrm{M}+\mathrm{MMT}$ \\
R6 & $14 \mathrm{M} 2 \mathrm{~T}$ & $\mathrm{TMM}+\mathrm{M}+\mathrm{M}+\mathrm{M}+\mathrm{M}+\mathrm{M}+\mathrm{M}+\mathrm{M}+\mathrm{M}+\mathrm{M}+\mathrm{M}+\mathrm{MMT}$ \\
R7 & $4 \mathrm{M} 4 \mathrm{~T}$ & $\mathrm{TM}+\mathrm{MT}+\mathrm{TM}+\mathrm{MT}$ \\
R8 & $4 \mathrm{M} 4 \mathrm{~T}$ & $\mathrm{TM}+\mathrm{TM}+\mathrm{MT}+\mathrm{MT}$ \\
\hline
\end{tabular}

basic unit of the train, where 0 represents the trailer, 1 represents the motor car and an empty array represents the unused units. Connect all the arrays together to get the entire train's code array C. For example, the code array of the R1 EMU train is defined as $\mathrm{C}=[0,1,1,0,0,1,1,0]$, indicating that it has eight vehicles and four units corresponding to four non-null arrays.

\subsection{Braking process simulation}

As shown in eqn (1), for a braking process, the target deceleration is related to acquired train speed and braking level. According to Ref. [6], the relation between target deceleration and actual deceleration can be modelled as second-order oscillation elements with time delay by eqn (2) where $s$ is the Laplace operator, $\tau$ is the time delay caused by braking signal transmission and clearance of brake callipers, $T 1$ is a constant about braking force response time and $T 2$ is a time constant of a first-order filter as an approximation of longitudinal jerk limitation. Considering the additional deceleration caused by running resistance, the total deceleration is calculated by eqn (3). Equations (4)-(5) calculate the velocity and braking distance. Subscript $k$ indicates the number of iterations.

$$
\begin{gathered}
a_{-} r e f_{k}=f\left(v_{k-1}, b l_{k}\right) \\
a_{k}(s)=\frac{a_{-} r e f_{k}(s) \cdot e^{-\tau s}}{T_{1} T_{2} s^{2}+\left(T_{1}+T_{2}\right) s+1} \\
a_{k}^{\prime}=a_{k}+a_{-} r e s_{k} \\
v_{k}=v_{k-1}-a_{k}^{\prime} \cdot \Delta t \\
x_{k}=x_{k-1}+\frac{v_{k-1}+v_{k}}{2} \cdot \Delta t
\end{gathered}
$$


Utilizing iterative calculations with eqns (1)-(5), we can get the deceleration, velocity and braking distance at each step of the whole braking process. Then electric braking forces, pneumatic braking forces and brake cylinder pressures can be calculated with the actual deceleration.

Braking force of a unit is self-sufficient by the unit itself. During a braking process, electric braking force of the motor car is applied first, and the insufficient part is replenished first by the trailer's pneumatic braking force, and then the remaining part is supplemented by the motor car's pneumatic braking force. In eqns (6)-(10), subscript $i$ represents the unit number, which takes 0-7 (integer).

$$
\begin{aligned}
& F_{i}=M_{i} \cdot a \\
& F E C_{i}=\frac{M_{i} \cdot a_{-} r e g \cdot U_{i}^{T}}{\operatorname{sum}\left(U_{i}\right)} \cdot U_{i} \\
& F E B_{i}=\frac{\min \left\{\operatorname{sum}\left(F E C_{i}\right), \operatorname{sum}\left(F_{i}\right)\right\}}{\operatorname{sum}\left(U_{i}\right)} \cdot U_{i} \\
& F A B_{i}=\left\{\begin{array}{l}
\mathrm{O}, \operatorname{sum}\left(F E C_{i}\right) \geq \operatorname{sum}\left(F_{i}\right) \\
\left(\operatorname{sum}\left(F_{i}\right)-\operatorname{sum}\left(F E C_{i}\right)\right) \cdot\left(1-U_{i}\right), F_{i} \cdot U_{i}^{T} \leq \operatorname{sum}\left(F E C_{i}\right)<\operatorname{sum}\left(F_{i}\right) \\
\frac{F_{i} \cdot U_{i}^{T}-F E B_{i} \cdot U_{i}^{T}}{\operatorname{sum}\left(U_{i}\right)} \cdot U_{i}+F_{i} \cdot\left(1-U_{i}\right), \operatorname{sum}\left(F E C_{i}\right)<F_{i} \cdot U_{i}^{T}
\end{array}\right. \\
& p B C_{i}=\frac{1}{A} \cdot\left(\frac{F A B_{i}}{n \cdot \varphi \cdot \delta \cdot \eta}+F_{s p r}\right)
\end{aligned}
$$

The meanings of the notifications used above are shown in Table 2.

Table 3 shows the simulation results using the method proposed in this article and results of a field test. For brake conditions of service brake level 7 and level 6, the errors of braking distance between simulation and test are all under $1 \%$.

\section{SIMULATION RESULTS AND DISCUSSION}

To prove the advantages of this method in the simulation of flexible marshalling EMU trains braking process, Fig. 4 shows the results of a simulation for a custom marshalling train consisting of three motor cars and two trailers. The units can be expressed as 'TM+MMT', which means it has two units, and one unit has one trailer and one motor car, the other has one trailer and two motor cars.

The simulation's braking level is emergency brake (EB) and the simulation speed is from $300 \mathrm{~km} / \mathrm{h}$ to 0 . The electric braking forces of each car are shown in Fig. 4a. The first and fifth 
Table 2: Definition of notifications in equations above.

\begin{tabular}{ll}
\hline Notations & Meanings \\
\hline a_ref & target deceleration \\
a_res & deceleration caused by resistance \\
a_reg & deceleration provided by electric braking force \\
$a^{\prime}$ & actual deceleration \\
$a$ & total deceleration \\
$v$ & velocity \\
$x$ & braking distance \\
$\Delta t$ & time step of simulation \\
bl & braking level \\
$M$ & vehicle mass \\
$F$ & total braking force \\
FEB & electric braking force \\
FEC & capacity of electric braking force \\
FAB & pneumatic braking force \\
pBC & brake cylinder pressure \\
$A$ & effective area of brake cylinder \\
$n$ & number of cylinders \\
$\varphi$ & friction coefficient of brake pads \\
$\delta$ & leverage \\
$\eta$ & mechanical efficiency \\
$F_{s p r}$ & spring force of the cylinder \\
\hline
\end{tabular}

Table 3: Comparison of simulation and test results for a type of existed train. ( $7 \mathrm{~N}$ means service brake level 7, 6N means service brake level 6.) (Source: Zhu et al. 2017.)

\begin{tabular}{llll}
\hline Conditions & Initial velocity $(\mathrm{km} / \mathrm{h})$ & Braking distance $(\mathrm{m})$ & Relative error \\
\hline $7 \mathrm{~N}$ test1 & 200.3 & $1,526.8$ & $0.43 \%$ \\
$7 \mathrm{~N}$ simulation1 & 200.3 & $1,520.2$ & \\
$7 \mathrm{~N}$ test2 & 159.9 & 953.0 & $0.67 \%$ \\
$7 \mathrm{~N}$ simulation2 & 159.9 & 946.6 & \\
$6 \mathrm{~N}$ test & 139.5 & 827.4 & $0.31 \%$ \\
$6 \mathrm{~N}$ simulation & 139.5 & 824.8 & \\
\hline
\end{tabular}



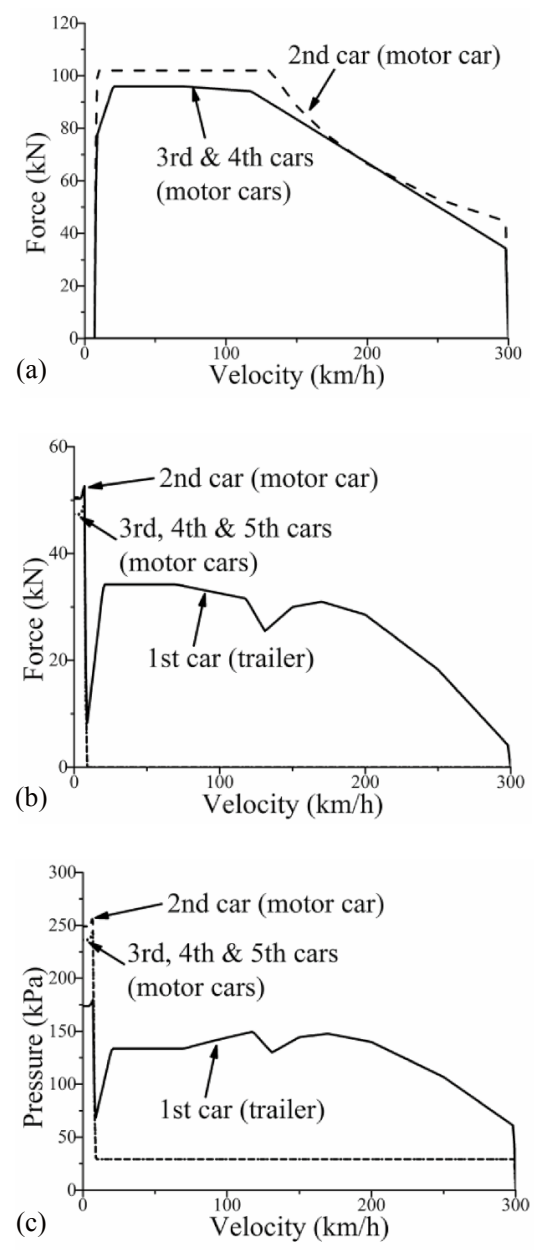

Figure 4: Simulation curves. (a) Electric braking forces; (b) pneumatic braking forces; (c) brake cylinder pressures.

cars are trailers, so the electric braking forces are constant zero. The second, third and fourth cars are motor cars, so the electric braking force of each car changes with velocity. Among them, the third and fourth cars belong to the 'MMT' unit so their electric braking forces are divided equally and less than the second car from the 'TM' unit.

As shown in Fig. 4b, the pneumatic braking forces are zero except the first car when velocity is above the electropneumatic conversion point $(8 \mathrm{~km} / \mathrm{h})$. Among them, the first and second vehicles belong to the TM unit, and the motor car in the unit cannot fully provide the required braking force for the trailer, so the first car's pneumatic braking force is not zero. The third, fourth and fifth cars belong to the same MMT unit. Before the electropneumatic conversion point, the internal braking force of the unit is provided by the electric braking forces of the two motor cars. Therefore, the pneumatic braking forces are all 0 until the speed is under $8 \mathrm{~km} / \mathrm{h}$, and then the pneumatic braking forces begin to rise after the conversion point. 
Figure $4 \mathrm{c}$ shows the pressure curves of the brake cylinders of cars. It is similar with Fig. $4 \mathrm{~b}$, but when the second, third, fourth and fifth cars' pneumatic braking forces are zero, the brake pressure is constant at $29.273 \mathrm{kPa}$ (pressure to overcome the spring force in the cylinder) instead of zero. The pressure of the brake cylinder starts to rise when the train speed is lower than the electropneumatic conversion point speed. The brake cylinder pressure of the first car changes with its pneumatic braking force during the whole process.

\section{CONCLUSIONS}

The simulation method proposed in this article is based on the actual process of train braking, from the receiving of braking instruction to the application of braking force. The braking force and the running resistance together constitute the deceleration force of the train. Then, the deceleration force acts on the train to decelerate the train until it stops or the speed is reduced to a certain end speed. In the whole process of braking, the changes of the electric braking forces and the brake cylinder pressures of all the cars can be simulated. EMU trains have a wide variety of types and different marshalling groups. Conventional methods are difficult to meet the needs of generalized simulation of different marshalling trains. In this article, a general train braking simulation method is proposed, which can not only cover the existing marshalling EMU trains, but also can facilitate the new design of novel marshalling trains. It can simultaneously perform calculations and electric-pneumatic braking force distribution for each unit of an EMU train consisting of up to 16 or even more cars.

\section{ACKNOWLEDGEMENTS}

This article is supported by National Natural Science Foundation of China (Grant No. U1534205) and Key Projects in the National Science \& Technology Pillar Program during the Twelfth Five-year Plan Period (Grant No. 2015BAG12B01).

\section{REFERENCES}

[1] Luo, Z., Wu, M., Zuo, J. \& Tian C., Modelling and model validation of an electropneumatic brake on subway trains. Proceedings of the Institution of Mechanical Engineers, Part F: Journal of Rail and Rapid Transit, 230(2), pp. 374-391, 2014. DOI: 10.1243/09596518JSCE188.

[2] Pugi, L., Malvezzi, M., Allotta, B., Banchi L. \& Presciani P., A parametric library for the simulation of a Union Internationale des Chemins de fer (UIC) pneumatic braking system. Proceedings of the Institution of Mechanical Engineers Part F: Journal of Rail \& Rapid Transit, 218(2), pp. 117-132, 2014. DOI: 10.1243/0954409041319632.

[3] Piechowiak, T., Pneumatic train brake simulation method. Vehicle System Dynamics, 47(12), pp.1473-1492, 2009. DOI: 10.1299/jsmec.44.594.

[4] Richer, E. \& Hurmuzlu, Y., A high performance pneumatic force actuator system: Part I - nonlinear mathematical model. Journal of Dynamic Systems Measurement \& Control Transactions of the Asme, 122(3), pp. 416-425, 2000. DOI: 10.1016/01968904(94)90082-5.

[5] Li Z., Yang H., Liu M. \& Liu J., Modeling and tracking control for braking process of high speed electric multiple unit. China Railway Science, 37(5), pp.80-86, 2016. DOI: 10.3969/j.issn.1001-4632.2016.05.11.

[6] Guo H. \& Xie K., Hammerstein model and parameters identification of EMU braking system. Journal of the China Railway Society, 36(4), pp.48-53, 2014. DOI: 10.3969/j. issn.1001-8360.2014.04.009. 
[7] Yu, Z. \& Chen D., Modeling and system identification of the braking system of urban rail vehicles. Journal of the China Railway Society, 33(10), pp.37-40, 2011. DOI: 10.3969/j.issn.1001-8360.2011.10.007.

[8] Yang, H., Yan, J. \& Zhang, K., Braking process modeling and simulation of CRH2 electric multiple unit. Third International Conference on Digital Manufacturing and Automation, pp. 264-267, 2012. DOI: 10.1109/ICDMA.2012.64.

[9] Zhu W., Wu M., Tian C. \& Zuo J., Integrated simulation platform of braking system of rolling stock based on multi-discipline collaborative analysis. Journal of Traffic \& Transportation Engineering, 17(3), pp. 99-110, 2017. DOI: 10.3969/j.issn.16711637.2017.03.011.

[10] Zuo, J., Wang, Z. \& Wu, M., Simulation model of air braking system for subway train. Journal of Traffic \& Transportation Engineering, 13(2), pp. 42-47, 2013. DOI: 10.3969/j.issn.1671-1637.2013.02.006.

[11] Zhu, W. \& Wu, M., Braking calculation of electric multiple units (EMUs). Journal of Tongji University, 45(1), pp. 119-123 and 134, 2017. DOI: 10.11908/j.issn.0253374x.2017.01.017. 